grains and coups de vent which would inform the airman of the approach of grave risks should he attempt an ascent until the squall has passed. So far back as $1892 \mathrm{M}$. Durand-Gréville made the suggestion to meteorologists in a menoir entitled "Les Grains et les Orages," which appeared in the Annales du Bureau central meteorologique de France. This memoir showed that the isochronic lines markins the commencement of storms corresponded with much longer isochrones of squalls. The name ruban de grain was attached to a more or less sinuous band extending from near the centre to the circumference of a depression. This band is often 1000-r $500 \mathrm{~km}$. (625-940 miles) long, and in its interior the wind is very strong, and often accompanied by precipitation. The advent of the squall is generally marked by a gentle south-west wind veering with startling suddenness and violence to the north-west, masses of cloud come up rapidly from the west, and frequently heavy thunder is heard. All these phenomena occur suddenly and practically simultaneously, so that the passing of the squall is easily and definitely observed.

M. Durand-Greville's proposal is that from those stations first passed over, telegraphic warnings should be immediately dispatched to centres lying eastwards in the subsequent path of the disturbance. Numerous experiments have demonstrated the feasibility and utility of the scheme. Stations west of Paris have sent messages announcing squalls which have subsequently passed over that city at the predicted time.

On the occasion of the great Aëronautical Congress at Frankfort during 1909 , the plan was tried by M. Linke, director of the meteorological station there. Fifty-five observers within a radius of $150 \mathrm{~km}$. were asked to notify the director of any squall which passed over their separate stations, and M. Durand-Gréville states that, "save in one or two cases, all the storms which visited Frankfort during this period were known to M. Linke more than an hour in advance."

M. Durand-Gréville points out that the expense to any body which undertook the organisation of the warnings would be almost negligible as compared with the money expended in prizes awarded to aviators, not to mention the much greater cost of machines, \&c., and the lamentable sacrifice of human life which might, at least to some extent, be obviated. The ordinary forecasts and warnings issued by the various national meteorological offices are far too general to be of use in this regard, but special services might be instituted, as a trial, by some of the societies especially interested in aëronautical matters.

\section{TEMPERATURE OF THE UPPER AIR.}

M. M. RYKACHEF has worked out the results of 1. balloon ascents at Pavlovsk, Kuchino near Moscow, Pavlovsk, thirty-two at Kuchino, and twelve at Olchedaief, some of which attained a height of 12 kilometres. Wilh regard to the yearly means, the temperature at Pavlovsk was up to $9 \mathrm{~km}$. lower than at Kuchino, the differences increasing up to 3 to $3.5 \mathrm{~km}$., and then diminishing. At $9 \mathrm{~km}$. they change sign, increasing up to a maximum of about $4^{\circ} \mathrm{C}$. between 10.5 and $12 \mathrm{~km}$. The difference of temperature between Pavlovsk and Nizhni Olchedaief is much greater, diminishes up to ro $\mathrm{km}$., where it changes sign, and attains a maximum of $I^{\circ}$ between $I I$ and $I 2 \mathrm{~km}$. A marked diminution in the fall of temperature takes place at a lower height in Pavlovsk than in Kuchino, and at Kuchino than at Olchedaief, the heights being 9.5 , 0.8 , and $10.8 \mathrm{~km}$. respectively. The temperature of the isothermic layers is highest at Pavlovsk and lowest at Kuchino. These variations may be explained by the differences of latitude, Pavlovsk being situated at about $60^{\circ}$, Kuchino $56^{\circ}$, and Nizhni Olchedaief $48^{\circ}$, while Pavlovsh is more exposed to the mild influence of a sea climate than the other two places.

At Nizhni Olchedaief the ascents were too few to deduce any satisfactory conclusions with regard to seasonal variations. At Pavlovsk the temperature at all seasons from the ground up to 8.5 to $9 \mathrm{~km}$. was lower than at Kurchino, except that in winter the temperature up to 500 metres was higher, which result accords with the readings taken on the ground for a series of years. The difference of NO. 2 I 49, VOL. 85] temperature in winter, spring, and autumn shows a marked increase at about 2.5 to $3 \mathrm{~km}$., changes sign at 8.5 to $9 \mathrm{~km}$., and rapidly increases to the isothermic layers, where the temperature is lower at Kuchino than at Pavlovsk. In summer the difference decreases continually up to $9.5 \mathrm{~km}$., and then changes sign and increases. The height where the fall in the temperature becomes in significant is lower in all seasons at Pavlovsk than at Kuchino, except in spring, when it is about $10 \mathrm{~km}$. at both stations.

The temperature of the isothermal region is markedly lower at Kuchino. In the curve of monthly means is seen a retardation of the maximum in the higher layers of air In the lower atmosphere the maximum occurs in July both at Pavlovsk and Kuchino, but at greater heights it occurs in August, the change taking place at a height of $2.5 \mathrm{~km}$. at Kuchino and at $4.5 \mathrm{~km}$. at Pavlovsk. At $9 \mathrm{~km}$. the maximum returns to July. The minimum exhibits somewhat similar variations. Amplitudes and gradients mean changes of temperature with elevation in cyclone and anticyclones, \&c., are also discussed, with numerous tables and diagrams, in an article published in the Bulletin of the Imperial Academy of Sciences of St. Petersburg, No. 7, I910.

\section{THE INCENSE-ALTAR OF APHRODITE AT} PAPHOS.

A $\mathrm{N}$ interesting article by Dr. Max Ohnefalsch-Richter appears in Globus of November 17 (xcviii., pp. 293-7), in which he brings forward data to prove his earlier supposition that the first site of Paphos was in the neighbourhood of Randi, in Cyprus. Certain inscriptions from this vicinity showed that Aphrodite, "the unconquerable," sender of Spring, was worshipped, and that an ancient incense-altar had existed there. The block containing the most important inscription is held by Prof. Richard Meister, of Leipzig, to belong to an incense-altar, and he adds that the incense-altar of Aphrodite at Paphos (Homer, VIII., 362; Homeric Hymns, IV., 59) was famous from earliest times.

Last August Dr. Ohnefalsch-Richter was able to identify a semi-subterranean side-chamber in the rock connected with this altar, whence had come the inscribed incensebowls which Prof. Meister has been deciphering. Dr. Zahn's excavations in the chamber have brought to light some half-dozen further inscriptions in the Paphian script, and he has made a number of valuable discoveries on the hill-side below, among them phalli which again played an important part in the Paphian Aphrodite-worship. The cult carried on on the hill consisted in making incense offerings, as described by Homer; in Dr. Zahn's opinion images were not used originally. A clay statue of about life-size was, however, found in the middle of the altarchamber, the style indicating a date about 600 B.c. The article concludes:- "We must wait to see what Prof. Meister will make of the hundred and more inscriptions discovered. As yet everything supports my surmise that on the hill of the incense-altar at Randi, not only an incense-altar of Aphrodite Paphia stood, but the mos: famous, the Homeric, incense-altar of Aphrodite of Paphos.'

Early in the article the writer refers to ten inscribed stones from Randi "from secret, prohibited excavations." which were fortunately purchased by someone who generously presented them to the Cyprus Museum. This is additional evidence, if such be required, of the urgent necessity for strong measures by the Government for the repression of illicit traffic in objects of archæological interest in this island and elsewhere.

\section{AIMS OF ASTRONOMY OF PRECISION. ${ }^{1}$}

THE science of precise physical measurement is one which does not readily appeal to those not immediately concerned, either with the methods or results. An authoritative statement that the sun's distance from the earth is $92,880,000$ miles may excite wonder, but scarcely more than will the statement that it is approximately

1 From the presidential address delivered before the Royal Society of South Africa on April 20, 1910, by S. S. Hough, F. R S. Published in the Transactions of the Society, vol. ii., part i. 